\title{
O POPULAR E 0 CONTEMPORÂNEO NO MUSEU DE ARTE COLEÇÕES E NARRATIVAS
}

Emerson Dionisio Gomes de Oliveira (UnB)

O presente artigo apresenta o modo como o Museu de Arte e de Cultura Popular da UFMT e outras instituições museológicas do Centro-Oeste administraram acervos com a presença de obras de arte classificadas como "contemporâneas" e "populares". A relação entre os dois vocabulários artísticos foi marcada com a transformação da cena artística da região por meio da negociação e do diálogo entre valores artísticos e patrimoniais exógenos e os agentes culturais locais, preocupados em emancipar e legitimar uma história da arte local.

\section{ARTE CONTEMPORÂNEA; ARTE POPULAR; MUSEU DE} ARTE.

OLIVEIRA, Emerson Dionisio Gomes de. O popular e o contemporâneo no museu de arte: coleções e narrativas. Textos escolhidos de cultura e arte populares, Rio de Janeiro, v.11, n.1, p. 129141, mai. 2014. 


\section{THE POPULAR AND THE CONTEMPORARY IN THE MUSEUM OF ART \\ COLLECTIONS AND NARRATIVES}

Emerson Dionisio Gomes de Oliveira (UnB)

This paper presents the way the Museum of Art and Popular Culture from the UFMT and other museum institutions in the Midwest manage collections comprised of works of art which are classified as "contemporary" and "popular". The relationship between the two artistic vocabularies was marked by the transformation of the region's art scene through negotiation and dialogue between artistic and patrimonial exogenous values and local cultural agents, focused on empowering and legitimizing the local art history.

CONTEMPORARY ART; POPULAR ART; MUSEUM OF ART.

BARBIERI, Ricardo José. Etnografia da galera do Caprichoso: simbolismo e sociabilidade entre jovens no festival de Parintins. Textos escolhidos de cultura e arte populares, Rio de Janeiro, v.10, n.2, p. 129-141, nov. 2013. 
Nas últimas quatro décadas do século XX uma segmentação nos sistemas das artes visuais acentuou-se com o crescente prestígio da arte contemporânea, mesmo quando um amplo e devotado debate sobre a produção material e imaterial de matrizes "populares" ganhava fôlego e visibilidade. A convivência entre a arte considerada de matriz popular e a arte contemporânea é um evidente ponto de tensão dentro das coleções de arte marcadas pela heterogeneidade e formadas desde os anos 60. As condições históricas dessa tensão têm operado em acervos públicos de arte, de modo a nos mostrar diferentes políticas de conservação e comunicação, e apresentam-nos propostas distintas que ora segregam a arte considerada popular, ora emancipam-na como arte atualizada (OLIVEIRA, 2010, p.82101). Tais coleções mostram-se espaços privilegiados para que possamos perceber o manejo do conceito de "popular" e suas significações aplicadas às artes visuais, bem como os modelos de assimilação e descarte operados pelas instituições gestoras dessas coleções.

A constituição e o enquadramento da produção artística "popular" apartada no sistema de reconhecimento acadêmico e mercadológico deram-se lenta e gradativamente ao longo do último século. Sob o questionável rótulo de "arte popular", todo um conjunto de obras produzidas fora dos âmbitos classificados como "cultos" foi assimilado pelas narrativas da história da arte e pelo sistema museal brasileiro. Esse conjunto foi inserido num processo de compreensão da produção popular mais ampla, no qual se destacaram a militância intelectual crítica e a supremacia do discurso erudito, num complexo jogo de representações que subordinava a cultura popular às categorizações. Enquanto noção histórica própria das artes visuais, a "arte popular" e suas imagens nasciam do interesse pelos temas regionais - por parte da literatura e do cinema -, da forte influência da música regional na incipiente indústria fonográfica, do nascimento das primeiras políticas voltadas para o patrimônio nacional, bem como do nascimento do turismo profissional em ampla escala.

A constituição da "arte popular", enquanto categoria assimilada pela história da arte, no primeiro momento, estava assinalada pela interpretação das obras como unidades estéticas coesas, ancoradas na emancipação do artista popular como criador autêntico. Na maioria dos casos, obras naturalizadas como expressão unívoca de uma dada comunidade ou classe social, em contraponto a uma produção artística constituída "por processos híbridos e complexos, usando como signos de identificação elementos procedentes de diversas classes e nações" (CANCLINI, 2003, p.220). De acordo com Price, tal categorização decorreu do processo que instituiu e normatizou a produção material dos povos considerados primitivos. Para ela há um paralelo entre o modo como os meios científicos e ar- 
tísticos se apropriam da arte "primitiva" proveniente de povos diferentes da organização ocidental e a fundação de lugar para os "primitivos" presentes nas sociedades "civilizadas", um lugar específico e hierarquizado. A arte proveniente das culturas africanas, ameríndias, asiáticas, etc. serviu para autorizar a discriminação, pela semelhança de funções ou formas, contra bens culturais de camponeses, operários, mulheres e homens "incultos", em complexa circulação, apropriação e reapropriação de representações dos "inferiores" sociais (PRICE, 2000).

Há dessa forma, para alguns segmentos e instituições de memória, certo embaraço quando instituições dedicadas ao fomento, à divulgação, à circulação e à memória das artes visuais em suas políticas aquisitivas e de conservação precisam computar juntas obras classificadas a priori dentro dos códigos da "cultura popular" e a chamada "arte contemporânea". Em centros culturais nos quais a variedade de instituições criou coleções segmentadas, o embaraço tornou-se menos evidente. Todavia, em outras comunidades, a carência de instituições que normatizassem a separação entre esses dois códigos artísticos tornou-se questão cada vez mais complexa à medida que a arte contemporânea foi estendendo seus domínios a regiões consideradas periféricas.

Não deixa de ser inquietante o fato de que, justamente entre matrizes poéticas que formaram a arte contemporânea desde o final dos anos 50, estejam códigos plásticos retirados das imagens "populares". Tais imagens foram concebidas em ambientes distintos. Enquanto artistas brasileiros bebiam na pop art estadunidense, cujos valores eram tomados de "um repertório icônico extremamente rico da cultura de massa suburbana e industrial, apropriado do horizonte cotidiano da sociedade de consumo" (ALVARADO, 1999, p.11), outros criadores se debruçavam sobre imagens confeccionadas em manifestações culturais populares, geradas pela simultânea manutenção e transformação de saberes de outrora. No primeiro grupo podemos encontrar nome de artistas que atualmente estão enquadrados nos valores da arte contemporânea, como Nelson Leiner, Claudio Tozzi, Antonio Henrique Amaral, Wesley Duke Lee, Rubens Gerchman, Wanda Pimentel, Antonio Dias, entre outros, sendo quase todos dedicados à releitura das imagens ordinárias ofertadas pela televisão, pela publicidade, pelas histórias em quadrinhos, fotonovelas, revistas semanais e jornais. Já no segundo elenco, destacam-se nomes como Raimundo de Oliveira, Wellington Virgolino, Abdias do Nascimento, Carybé, Mestre Didi (Deoscoredes dos Santos), Emmanuel Nassar, Rubem Valentim, Genaro de Carvalho, Antonio Poteiro, dentre outros.

Uma pesquisa detalhada sobre esses dois grupos - que, entretanto, excede as ambições deste artigo - pode revelar, todavia, que os processos de celebração e colecionamentos de suas obras não foram exatamente idênticos, mesmo 
que todos tenham sido assimilados pelo universo classificatório da arte contemporânea. Tal processo, complexo e particular, não é atual e não chega a configurar-se numa novidade para historiadores e cientistas sociais de diferentes geografias. Ele remonta mesmo à construção da arte moderna, ou melhor, de uma cultura moderna no Brasil. Alguns intelectuais foram cruciais no apartamento e na delimitação da "arte popular". De Sílvio Romero a Silva Mello, passando por Câmara Cascudo, Gilberto Freyre e Mário de Andrade, ${ }^{1}$ a consciência de uma produção material distinta daquela cortejada pelas clássicas classificações foi sendo sedimentada no amplo, difuso e heterogêneo rótulo de cultura popular. Para Lélia Coelho Frota (1986, p.11), a descoberta das artes populares "é consequência de um processo histórico cultural ligado à filosofia do movimento modernista de 1922 e do movimento regionalista do Recife, iniciado naquela cidade em 1923". Ela ainda lembra que:

Os próprios artistas populares não foram absolutamente agentes passivos de seu processo de gradual reconhecimento pois, também por seu lado, experimentavam mudanças em relação ao seu meio cultural, fazendo uma síntese formal própria, como qualquer outro artista, das transformações que viam acontecer diante de seus olhos e que também os motivavam (...). Esses novos trabalhos apresentam a construção de um estilo comparável aos dos artistas de norma culta, e destinam-se agora à clientela de maior poder aquisitivo das galerias de arte e museus (FROTA, 2005, p.31).

Sendo assim, além da participação ativa dos criadores, a visibilidade dessa produção é indiciada como resistência pelas instituições patrimoniais desde os anos 30. Todo um conjunto de objetos e práticas herdadas do passado que se apresenta como testemunha de distintos estilos de vida, geralmente do universo rural e menos abastado.

Essa perspectiva traz como consequência a mitificação da noção de popular, idealizada enquanto cultura 'autêntica', 'pura', testemunho de uma realidade de outrora, mais nobre, que caberia a todo custo conservar e defender de influências espúrias, posto que lhe cabe o papel ora melancólico, de sobrevivência condenada ao desaparecimento, ora redentor, de representante das raízes, da identidade e da nacionalidade (LIMA, FERREIRA, 1999, p.112).

É nessa perspectiva que Michel de Certeau (1995) lembra de que esse processo de delimitação da arte e da cultura popular pressupõe uma ação não confessada. Para ele, foi preciso censurar a produção "popular" para poder estudála. "Tornou-se, então, um objeto de interesse, porque seu perigo foi eliminado" (p.55-56). 
O temor desse "perigo" pode ser percebido na história do sistema museal voltado para as artes visuais no Brasil. Desde a primeira metade do século XX, coleções de "arte popular" foram apartadas das coleções provenientes das matrizes classificatórias clássicas da história da arte. No momento em que é aberta a mostra Exposição de Cerâmica Popular Pernambucana, na Biblioteca Castro Alves do Instituto do Livro, no Rio de Janeiro, em 1947, iniciava-se uma longa marcha de musealização da "arte popular" brasileira, prefigurada na obra de Mestre Vitalino, um símbolo dessa institucionalização:

Vitalino Pereira dos Santos, Mestre Vitalino, é figura emblemática na arte popular brasileira. Foram as suas esculturas que despertaram a atenção dos grandes centros urbanos para o vasto território da criação plástica popular. Apresentado ao grande público em 1947, numa exposição coletiva organizada pelo artista plástico e criador da Escolinha de Arte do Brasil, Augusto Rodrigues, no Rio de Janeiro, na qual eram mostradas obras de artesãos e artistas pernambucanos, Mestre Vitalino tornou-se, juntamente com seu compadre Zé Caboclo e com Manuel Eudócio, uma das principais figuras do mundo da arte popular, até então tão pouco divulgado (MASCELANI, 2002, p.14).

Ao lado de Vitalino na construção de um "acervo" artístico, destacados ainda estavam os pintores Heitor dos Prazeres, artista presente na I Bienal Internacional de São Paulo, em 1951, e José Antônio da Silva, chamado a representar o país na 26a Bienal de Veneza, em 1952. Um certo "gosto pelo primitivo" (FRADE, 2004, p.19) instaura-se na sociedade contemporânea. A partir desse momento iniciava-se um processo de colecionamento privado, em que se destacaram nomes como Abelardo Rodrigues, Lina Bo Bardi, Jacques van de Beuque, João Maurício Pinho, Emanoel Araujo, Gianzia Imazio, entre outros. ${ }^{2}$

\section{COLEÇÕES PÚBLICAS NO INTERIOR DO BRASIL}

No Centro-Oeste temos realidades históricas distintas quando se trata da relação de colecionamento, em instituições públicas, da arte popular e da arte contemporânea. Em Goiânia, o Museu de Arte Contemporânea (MACG), instituição fundada em 1987, optou por seccionar o acervo em pequenas coleções, diferenciado-as no que concerne à política de comunicação e visibilidade. As obras classificadas como arte popular não ganharam visibilidade na última década. Já o Museu de Arte de Goiânia (MAG), seu congênere mais antigo, fundado em 1970, preferiu fundir as duas realidades, dando preferência por fazer-se representar por um elenco já consagrado de artistas locais. O MAG posicionou seu acervo do lado daqueles que creem que um museu de arte, mesmo na cena atual, deve 
comportar-se como um lugar de memória, no sentido que Pierre Nora (1993, p.728) confere ao termo, diferentemente do MACG, filiado à corrente que vê os museus atuais, prioritariamente, como formuladores de políticas aquisitivas da arte contemporânea mais experimental e atualizada. Nesse sentido, o MAG - tomado pelas escolhas desde 1997 - tenta instituir-se como guardião da cena artística goianiense, atrelando-se à própria história da cidade e elegendo, como elenco representativo, artistas renomados e conhecidos, dos quais Antonio Poteiro se destaca como um nome crucial para nosso problema. No campo das relações simbólicas, o MAG impele sua representação junto a certa "modernidade" da cidade, como índice e prova da "capital cultural", ao passo que também elege, na cena artística local, apenas artistas consagrados, computados aqueles dedicados ao popular. O sentido que se pretende representar está muito mais atrelado ao passado recente do que à promessa de continuar atento à produção hodierna.

Em Campo Grande, o Museu de Arte Contemporânea do Mato Grosso do Sul, fundado em 1991, opera pela elevação da arte popular a elemento da prática artística contemporânea. O Marco tem procurado amainar o debate entre arte e artesanato e, para tanto, celebra três artistas de forte relação com a cultura local, popular/indígena e suas apropriações identitárias. O museu sul-mato-grossense procura aproximar-se da produção da arte contemporânea, sem abrir mão de manejar a produção de apelos identitários, identificada com a arte popular. Uma configuração semelhante ocorre com a coleção do Museu de Arte Contemporânea de Jataí, fundado em 1995, em Goiás, o qual, no entanto, nos últimos cinco anos, tem procurado abrir-se para a produção daquilo que o museu denomina uma arte mais "atualizada".

Por sua vez, o Museu de Arte de Brasília, inaugurado em 1985, optou por uma lenta e gradativa política de desaquisição da coleção de "arte popular" herdada da Fundação Cultural do Distrito Federal. Ou seja, embora a arte local não merecesse distanciar-se da nacional, no caso da capital brasileira, parte considerável dela deveria ser apartada sob a nomenclatura de "popular" e transferida para outro acervo. ${ }^{3} \mathrm{~A}$ coleção brasiliense optou pela assimilação da arte contemporânea, vinculada aos centros culturais hegemônicos.

É dentro dessa sintética indicação que trazemos para nossa discussão a experiência contrapontística ofertada pelo Museu de Arte e de Cultura Popular da Universidade Federal do Mato Grosso, criado pelos artistas e críticos Aline Figueiredo, Therezinha Arruda e Humberto Espíndola, em 1974.

Sabemos a importância do papel que Figueiredo teve na consolidação de uma retórica que valorizasse a arte regional por meio de seus aspectos nativos. Sua militância, desde o final dos anos 60 , tem enfrentado o difícil caminho aber- 
to pelas categorias afiliadas e sobrepostas da "arte popular", da "arte primitiva" e da "arte regional":

Como dizia, deve-se expressar essa visualidade toda, desprezando, porém, os excessos de detalhes, a soltura ou a improcedência de elementos, o sentido ilustrativo e fácil que tornam obras desse tipo, meramente regionalistas ou folclóricas. Somos pelo regional e é a nossa bandeira. Mas somos contra a pieguice regionalista que não consegue extrapolar os horizontes, exatamente porque não tem subsídios de argumento, nem reflexão, nem plástica e muito menos visual. Somos por uma arte brasileira com raízes regionais bem definidas e bem posicionadas dentro de um discurso temático, cujas formas, pela inovação e qualidade, transcendam para a esfera universal. Em outras palavras, que seja bom aqui ou no Japão. (SALÃO DE..., 1982, p.4-5).

O Museu de Arte e de Cultura Popular (MACP) é decorrente de uma série de ações de Figueiredo e Espíndola desde 1966, com a realização, em Campo Grande, da Primeira Exposição de Artistas Mato-Grossenses. A exposição singular para as políticas governamentais dedicadas às artes plásticas foi seguida da criação da Associação Mato-Grossense de Arte, em 1967, e pela criação da Universidade Federal do estado, em 1970. O MACP foi criado em torno do conceito de museu-ação, "organismo vivo e em constante interação com a comunidade e que viabilizou o potencial criativo da região" (FIGUEIREDO, ESPÍNDOLA, 2010, p.16). Instituído com a missão de compreender três pilares da cultura (arte brasileira, cultura popular e indigenismo), o museu buscou, desde os primeiros anos, a atualização da arte brasileira e o apoio do artista mato-grossense. "O Museu de Arte e Cultura estabeleceu a ruptura com o anacrônico e criou um público receptivo ao contemporâneo" (IDEM).

Em 1976, é criado o projeto mais ousado do museu: Ateliê Livre, voltado para ministrar cursos e realizar mostras para a comunidade. ${ }^{4}$ Articulado por Dalva de Barros e Humberto Espíndola, o projeto teve, entre seus primeiros participadores, os moradores de Caxipó, bairro em que estava situado o campus da universidade. Sobre a participação dos artistas do Ateliê no Salão Jovem Mato-Grossense, "Houve imenso cuidado em preservá-los da massificação do mercado que poderia desviá-los da busca criativa. O quanto pôde fizemos para garantir-lhes a despreocupação com o sustento, para que nos garantissem a preocupação com a pintura" (FIGUEIREDO, ESPÍNDOLA, 2010, p.17).

No eixo que buscava trazer ao estado a produção contemporânea, o museu realizou mostras individuais e coletivas com artistas com carreiras nacionais: Luiz Zerbibi, Bené Fonteles, Cildo Meireles, Rubem Valentim, Daniel Senise, Áu- 
Figura 1: Dona Joana e Domingas (atribuição), Moça-moringa, s.d., cerâmica, 33 × 20 × 19cm; acervo do Museu de Arte e de Cultura Popular/ UFMT Fonte: Figueiredo e Espíndola (2010)

Figura 2: Adir Sodré, Almoço na relva, 1995, acrílica sobre tela $162 \times 110 \mathrm{~cm}$; acervo do Museu de Arte e de Cultura Popular/ UFMT Fonte: Figueiredo e Espíndola (2010)

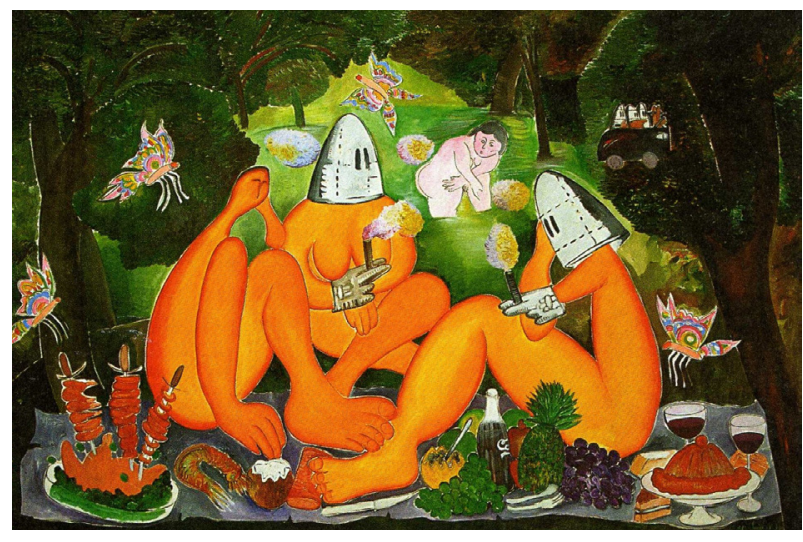

rea Katsuren, Gilberto Salvador, Rubens Gerchman, Luiz Áquila, Takashi Fukushima, Ângelo Venosa, Nelson Maravalhas, Tunga, Paulo Fogaça, Márcio Sampaio, entre outros. Além de receber críticos de peso, como Clarival Valadares, Frederico Morais, Roberto Pontual, Mario Barata e Aracy Amaral. No que concerne ao "indigenismo", o museu acolheu obras de Valdir Sarubi, Conceição Freitas da Silva, Edival Ramosa, Clóvis Irigaray, além de propostas poéticas de artistas que se adaptaram ao tema "índio" de modo crítico: Rubens Gerchman, Gilberto Salvador e Cristiano Mascaro.

A "arte popular", por sua vez, estava presente graças às mostras de Valdelino Lourenço e de Antonio Poteiro, e também na própria criação do museu. No período imediatamente anterior à criação da instituição, Therezinha Arruda estava empenhada em divulgar e preservar parte da produção ceramista das comunidades ribeirinhas do rio Cuiabá, entre elas a emblemática comunidade de São Gonçalo, cujos artistas - como Biuína Moura, Joana e Domingas Silva e Clínio Moura - se tornaram símbolos de resistência de uma arte que parecia na época ameaçada pelo esquecimento (Figura 1). Foram as peças desses artistas que marcaram o início do acervo do MACP.

Ponto crucial para compreensão de como o museu lida com a problemática da "arte popular" repousa no enfretamento da pluralidade dessa terminologia. Trabalhos díspares, como os ofertados pelo núcleo ceramista de São Gonçalo até trabalhos como os de Adir Sodré (Figura 2), cuja temática já inclui uma releitura da arte canônica europeia, foram assimilados pelo acervo do museu dentro 


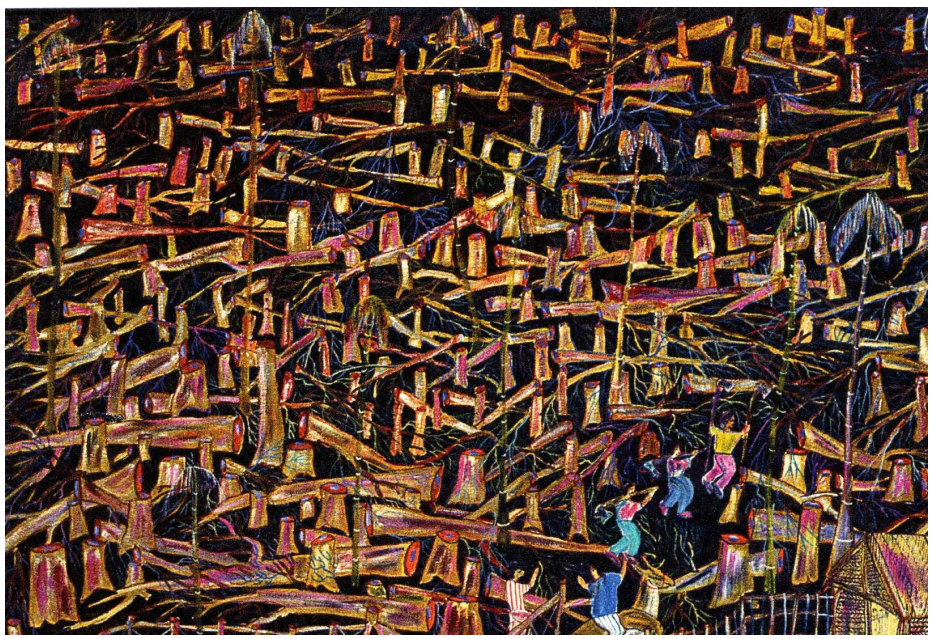

Figura 3: Nilson Pimenta, Derrubada, 1986, óleo sobre tela, $80 \times 120 \mathrm{~cm}$; acervo do Museu de Arte e de Cultura Popular/UFMT Fonte: Figueiredo e Espíndola (2010)

da compreensão polissêmica do que vem a ser "cultura popular" e seus difíceis imbricamentos com a cultura de massa, os processos identitários regionais e a tradições indígenas e afrodescentes da região. Nomes como Clovis Irigary, Alcides Pereira dos Santos, Nilson Pimenta, Benedito Nunes, Sebastião Silva, Maty Vitart e Miguel Penha expressam essa multiplicidade de fontes e repertórios visuais que acabam por solapar a imagem da "arte popular" enquanto categoria agregadora.

Mesmo que o MACP continue atrelado a certa ideologia identitária que busque preservar o "regional" e o "popular", uma breve consulta a seu acervo demonstra que, se a intenção de seus fundadores era desestabilizar as fronteiras entre uma arte "erudita" e uma "arte popular", suas ambições parecem-nos subestimadas. De fato, a coleção do museu, em toda a sua multiplicidade de elementos, coloca a própria dicotomia em questão. Talvez a dificuldade de tipificar essa variedade tenha cunhado a expressão "pintura cabocla", que serviu de mote para a mostra Brasil Cuiabá: Pintura Cabocla, realizada, em 1981, no Museu de Arte Moderna do Rio de Janeiro e, posteriormente, apresentada no MAM-SP e no Teatro Nacional de Brasília. Para Espíndola, a pintura cabocla era fruto de um movimento que só poderia ter lugar no interior do Brasil:

Acredito que para ser ver no mato é preciso de um tempo, como para se ver no escuro. Não entendemos esse grupo como de artistas ínsitos ou primitivistas. Certamente que há esses artistas, porém são poucos e o que existe é verdadeiramente autêntico, produto do mato com toda força rude e inventiva que consideramos rari- 
dade em nossos dias. Cito dois exemplos latentes em nosso meio: Alcides Pereira e Nilson Pimenta (SALÃo NACIONAL..., 1981, p.18).

Diferentemente de outras instituições museológicas dedicadas à produção de matrizes populares, o museu mato-grossense explicita que a categoria "popular" torna-se, de fato, um refúgio para aqueles empenhados em sua manutenção memorial e, ao mesmo tempo, um espaço discriminado da produção visual contemporânea. Tal modelo de gestão da coleção encontra eco na utopia proposta por Ferreira Gullar, no início dos anos 60, para o Museu de Arte Popular em Brasília. Para o crítico e poeta, todavia, a tarefa foi mais árdua. Em entrevista publicada em 1979, ele relatou:

Tive a ideia de criar o Museu de Arte Popular em Brasília, trazendo o material de arte popular do Brasil inteiro para botar no museu que o Oscar Niemeyer desenhou (...), ao mesmo tempo pensava em criar um atelier de arte popular em Brasília. Botar candango que veio do Nordeste para desenvolver esse tipo de atividade, lançando mão de sua experiência. O que era arte de vanguarda foi fácil fazer. Agora, o desenvolvimento do setor popular não foi possível, porque o candango saía de casa às seis da manhã, trabalhava o dia inteiro, voltava de caminhão para casa... Exausto! (apud couTO, 2004, p.168).

Tanto o projeto não realizado de Gullar quanto aquele que modelou o MACP contêm uma espécie de denominador comum: a necessidade de marcarse por meio de uma identidade local própria, uma consciência política aguda e a convivência entre distintas possibilidades de produção artísticas. No caso do museu, como bem expressa a ambiguidade do conceito de pintura cabocla, o "popular-local", ou uma possível "arte contemporânea-regional", aparece como tentativa de emancipação de uma arte vernacular, para além dos enquadramentos esquemáticos impostos à nomenclatura "popular". As aspas são particularmente importantes, em virtude de as identidades "populares" se tornarem incertas, semeando mais dúvidas do que fixações. Nesse tocante, no continente das artes visuais, é preciso reconsiderar os modelos classificatórios operados pela história da arte e o sistema museológico. A história do acervo do MACP nos oferece a possibilidade de questionar os valores que orientam as separações entre museus de arte e museus de "outras" artes.

\section{NOTAS}

1 Mário de Andrade foi crucial na convergência entre uma categorização da "arte popular" e dos processos patrimoniais. Ele acreditava que ao Estado cabia o patrocínio de expedições de coleta folclórica e a preservação dos elementos 
selecionados em ambientes museais adequados. Mas não só. Quando propunha a criação de expedições, sua finalidade não estava apenas endereçada ao papel coletor, mas, sim, a uma trama pedagógica que visava, entre outras coisas, a um "museu de reproduções", cuja meta era a de levar a regiões remotas um pouco das artes plásticas produzidas nos centros urbanos (CHAGAS, 2006).

20 processo é mais complexo e encontra na Campanha de Defesa do Folclore Brasileiro de 1958 e nas ações posteriores uma série de desdobramentos que fixarão o que se conhecer como "arte popular" e um elenco circunscrito de criadores no campo das artes plásticas (OLIVEIRA, 2012).

3 Uma avaliação realizada na abertura do museu, pelo museólogo e crítico João Evangelista de Andrade Filho, expressa a falta de prestígio da coleção tipificada como "arte popular": "Os naifs de Brasília não possuem a sofisticação dos iugoslavos, a plasticidade dos mexicanos, o dramatismo dos haitianos e belgas. Não se caracterizam também pelo preciosismo decorativo ou pela complexidade mítica, mas pela simplicidade e leveza que se sobressaem também, por exemplo, na obra do americano Horace Pippin, da francesa Albetine e na de muitos primitivos italianos." (MUSEU DE ARTE DE BRASÍLIA, 1985, p. 15). Tal coleção foi transferida, em 2007, para o Museu Vivo da Memória Candanga.

4 Inicialmente atrelado à Fundação Cultural, entre 1976 e 1979, o projeto passa a pertencer definitivamente à universidade em 1981.

5 Nestor García Canclini (2003, p.21) adverte que o termo "erudito" é demasiadamente problemático: "É preferível falar em culto, elitista, erudito ou hegemônico? Essas denominações se superpõem parcialmente e nenhuma é satisfatória. Erudito é a mais vulnerável, porque define essa modalidade de organizar a cultura pela vastidão do saber reunido, enquanto oculta que se trata de um tipo de saber: não são eruditos também o curandeiro e o artesão?".

\section{REFERÊNCIAS BIBLIOGRÁFICAS}

ALVARADO, Daisy V. M. Peccinini de. Figurações Brasil anos 60: neofigurações fantásticas e neo-surrealismo, novo realismo e nova objetividade brasileira. São Paulo: Itaú Cultural: Edusp, 1999.

CANCLINI, Nestor. Culturas híbridas: estratégias para entrar e sair da modernidade. São Paulo: Edusp, 2003.

CERTEAU, M. de. A cultura no plural. Tradução Enide Abreu Dobránszky. Campinas: Papirus, 1995.

CHAGAS, Mário de Souza. Há uma gota de sangue em cada museu: a ótica museológica de Mário de Andrade. Chapecó: Argos, 2006. 
COUTO, Maria de Fátima Morethy. Por uma vanguarda nacional: a crítica brasileira em busca de uma identidade artística (1940-1960). Campinas: Ed. da Unicamp, 2004.

FIGUEIREDO, Aline; ESPÍNDOLA, Humberto (Org.). MACP: animação cultural e inventário do acervo do Museu de Arte e Cultura Popular da UFMT. Cuiabá: Entrelinhas, 2010.

FRADE, Isabela. O lugar da arte: o paradigma multicultural frente ao primitivismo. Textos Escolhidos de Cultura e Arte Populares, v. 1, 2004.

FROTA, Lélia Coelho. Mestre Vitalino. Recife: Fundação Joaquim Nabuco, Massangana, 1986.

FROTA, Lélia Coelho. Pequeno dicionário da arte do povo brasileiro: século XX. Rio de Janeiro: Aeroplano, 2005.

LIMA, Ricardo Gomes; FERREIRA, Claudia Marcia. O museu de folclore e as artes populares. Revista do Patrimônio Histórico e Artístico Nacional, Rio de Janeiro, n.28, p.101-119, 1999.

MASCELANI, Angela. O mundo da arte popular brasileira. Rio de Janeiro: Museu Casa do Pontal: Mauad, 2002.

MUSEU DE ARTE DE BRASÍLIA. Catálogo de acervo e exposição. Brasília, 1985.

NORA, Pierre. Entre memória e história: a problemática dos lugares. Projeto História, São Paulo, n.10, p.7-28, dez. 1993.

OLIVEIRA, Emerson Dionisio G. de. Museus de fora: a visibilidade dos acervos de museus de arte contemporânea no Brasil. Porto Alegre: Zouk, 2010.

OLIVEIRA, Vânia Dolores Estevam de. A patrimonialização da memória da cultura popular brasileira no Museu de Folclore Edison Carneiro. Revista Museologia \& Interdisciplinaridade, Brasília, v.1, n.1, p.135-164, jan.-jul. 2012.

PRICE, Sally. Arte primitiva em centros civilizados. Tradução Inês Alfano. Rio de Janeiro: Ed. da UFRJ, 2000.

SALÃO DE ARTES PLÁSTICAS DO MATO GROSSO DO SUL, 1, 1982, Campo Grande. Catálogo... Campo Grande: FCMS: SDS, 1982.

SALÃO NACIONAL DE ARTES PLÁSTICAS, 4, 1981, Rio de Janeiro. Mostra de arte... Rio de Janeiro: Funarte, 1981.

Emerson Dionisio Gomes de Oliveira é professor de história da arte na Universidade de Brasília. Docente do Departamento de Artes Visuais e do Programa de Pós-Graduação em Arte da Universidade de Brasília. Autor de Museu de fora (Zouk, 2010) e editor-chefe da Revista Museologia e Interdisciplinaridade. A atual pesquisa foi desenvolvida com o apoio do CNPq.

Recebido em: 15/04/2014

Aceito em: 30/04/2014 
